\title{
Assessing the flexibility of the Analytic Hierarchy Process for prioritization of invasive plant management
}

\author{
Abraham M. Nielsen', Songlin Fei ${ }^{2}$ \\ I Department of Forestry, University of Kentucky, 214 Thomas Poe Cooper Building, Lexington, KY 40546 \\ 2 Department of Forestry and Natural Resources, Purdue University, 715 West State Street, West Lafayette, IN \\ 47907
}

Corresponding author: Abraham Nielsen (abe.nielsen@uky.edu)

Academic editor: Brad Murray | Received 18 March 2015 | Accepted 10 August 2015 | Published 15 September 2015

Citation: Nielsen AM, Fei S (2015) Assessing the flexibility of the Analytic Hierarchy Process for prioritization of invasive plant management. NeoBiota 27: 25-36. doi: 10.3897/neobiota.27.4919

\begin{abstract}
Decision tools have been advocated to assist the prioritization of management areas for preventing and mitigating exotic invasions into native ecosystems. Currently, most tools have been created for specific invaders/regions and are thus often not sufficient to address the complex range of invasion scenarios that managers encounter. As exotic invasions continue to be a major issue, science-based, information-driven tools are pressingly needed. In this study, we explore the potential of utilizing the Analytic Hierarchy Process (AHP), one of the information-driven tools, to flexibly prioritize various invasion scenarios by incorporating a broad spectrum of management data. We tested the flexibility of the AHP management tool with two distinct invasion-stage-specific prioritizations for Amur honeysuckle (Lonicera maackii). The AHP tool successfully created two management prioritizations from contrasting invasion scenarios of established Amur honeysuckle invasion versus a hypothetical scenario of newly invading populations. The flexibility of AHP allowed users to alter input based on the stage of invasion in each scenario. In the established scenario, management priority was assigned to removing Amur honeysuckle from the most ecologically significant areas. For the new invasion scenario, priority was shifted to removing the invader from areas of most recent invasions. The two contrasting prioritizations demonstrate the flexibility of AHP as a management tool. We conclude that the flexible AHP tool could be useful for prioritizing management of exotic plant invasions.
\end{abstract}

\section{Keywords}

Analytic Hierarchy Process, modeling, invasive plant management

Copyright Abraham M. Nielsen, Songlin Fei. This is an open access article distributed under the terms of the Creative Commons Attribution License (CC BY 4.0), which permits unrestricted use, distribution, and reproduction in any medium, provided the original author and source are credited. 


\section{Introduction}

Invasive species are a growing problem both economically and ecologically. As these species continue to spread and invade new regions, managing to reduce their impacts becomes crucial (Byers et al. 2002, Ricciardi et al. 2013). Managers often face a suite of invasive species and large infested areas, making it a necessity to prioritize management actions (Hiebert 1997, Skinner et al. 2000). Many studies have examined the characteristics, spread, and potential impacts of invasive species, leading to generalizations about invasion ecology (e.g., Ehrenfeld 2010, Simberloff et al. 2012, Fei et al. 2014). Yet, effective management guidelines can be limited as the extensive knowledge and data associated with invasion ecology at the landscape scale can result in complex management scenarios. There is a need for science-based, information-driven tools to assist management decision-making.

Frameworks that analyze relevant information to facilitate the decision making process are known as decision tools. While decision tools have been used for a number of management purposes, such as prioritizing various conservation efforts (Sarakinos et al. 2001, Moilanen et al. 2005, Pert et al. 2013, Peterson et al. 2013), they have received less attention in the field of invasive species management. Moreover, existing applications of decision tools in invasion management were built to address a specific stage of the invasion process. For instance, certain models focus on preventing the introduction of high impact invaders (Cunningham et al. 2004) while others prioritize management areas based on detection, spread, or impacts of the invaders (Taylor and Hastings 2004, Mehta et al. 2007, Cook et al. 2007). Individually, these static models are not suitable to address the complex range of invasion scenarios that managers often encounter.

One such tool capable of incorporating a range of invasion data for prioritization modeling is the Analytic Hierarchy Process (AHP). In broad terms, AHP leads users through the decision making process by comparing input data in a pairwise manner that leads to priority (Saaty and Vargas 2001). By reducing complex decisions to a series of pairwise comparisons, expert judgement is incorporated into the decision process resulting in an objective ranking of the data. AHP has been applied in various fields and successfully produced prioritization outputs for forest conservation (Valente and Vettorazzi 2008) and landfill site selection (Zelenović Vasiljević et al. 2012).

However, there has been limited use of AHP for invasive plant management. Existing applications of AHP in invasion management are often region or species-specific (e.g., Roura-Pascual et al. 2009, Forsyth et al. 2012, Hohmann et al. 2013). Moreover, these studies do not directly demonstrate to managers that the AHP tool is adaptable to their specific management scenarios. Therefore in order to test the flexibility of AHP, we assessed if one tool could adapt to different management scenarios. We used two contrasting invasion scenarios, early versus late stage invasion of an exotic plant, for AHP assessment. We also assessed how the flexibility of the AHP management tool altered management priority between scenarios and further discussed how this flexibility could be useful for managers. 


\section{Methods}

\section{Model species}

Amur honeysuckle (Lonicera maackii) (Rupr.) Herder, a widely distributed and highimpact invasive exotic plant, was used as our study species to assess the AHP management tool. Amur honeysuckle is native to eastern Asia and is found in most states of the eastern United States. Amur honeysuckle forms dense understory patches with thick canopies and often results in a monocultural system that impacts native species, alters nutrient cycling, prohibits natural regeneration processes, and degrades the habitat for wildlife (Gorchov and Trisel 2003, McKinney and Goodell 2010, Dutra et al. 2011, Watling et al. 2011). Many forested areas have been or will be impacted by the invasion of Amur honeysuckle.

\section{Study area}

The Inner Bluegrass physiographic region of Kentucky, USA served as the general study area and covers approximately $5,000 \mathrm{~km}^{2}$ (Figure 1a). The Inner Bluegrass region is largely defined by limestone formations and phosphate rich silt loam soils (Wharton and Barbour 1991). The regional climate is characterized as temperate, humid, and continental (Wharton and Barbour 1991). Amur honeysuckle is widespread and found in thick patches throughout this region.

\section{AHP management tool}

In general, there are two initial steps in AHP workflow. In the first step, a manager sets a goal, such as prioritizing areas for the removal of an invasive exotic plant. As is often the case, complete removal from all locations isn't feasible, and management must be prioritized based on a preset of information. The second step of AHP is gathering the data (parameters) that will be used in the decision making process. Spatial data representing different characteristics of the invasion process and relevant to invasive plant management were selected for our analysis. To fit the structure of AHP, the parameters were placed into a hierarchy system that organizes the data into groupings at various levels. At the highest level, the parameters were grouped into one of three categories: Invasive Exotic Plant (IEP) Attributes, Ecological Impacts, or Land Use Characteristics. At the lowest level of the hierarchy, the descriptive information (attributes) of each parameter is assigned to individual management units (e.g. density level of plant infestation - low, medium, or high). The data organized into categories, parameters, and attributes, along with descriptions and data sources can be found in Table 1 .

AHP outputs were generated by using two different scenarios of Amur honeysuckle invasion, one actual and one hypothetical, in order to examine AHP flexibility. The first 


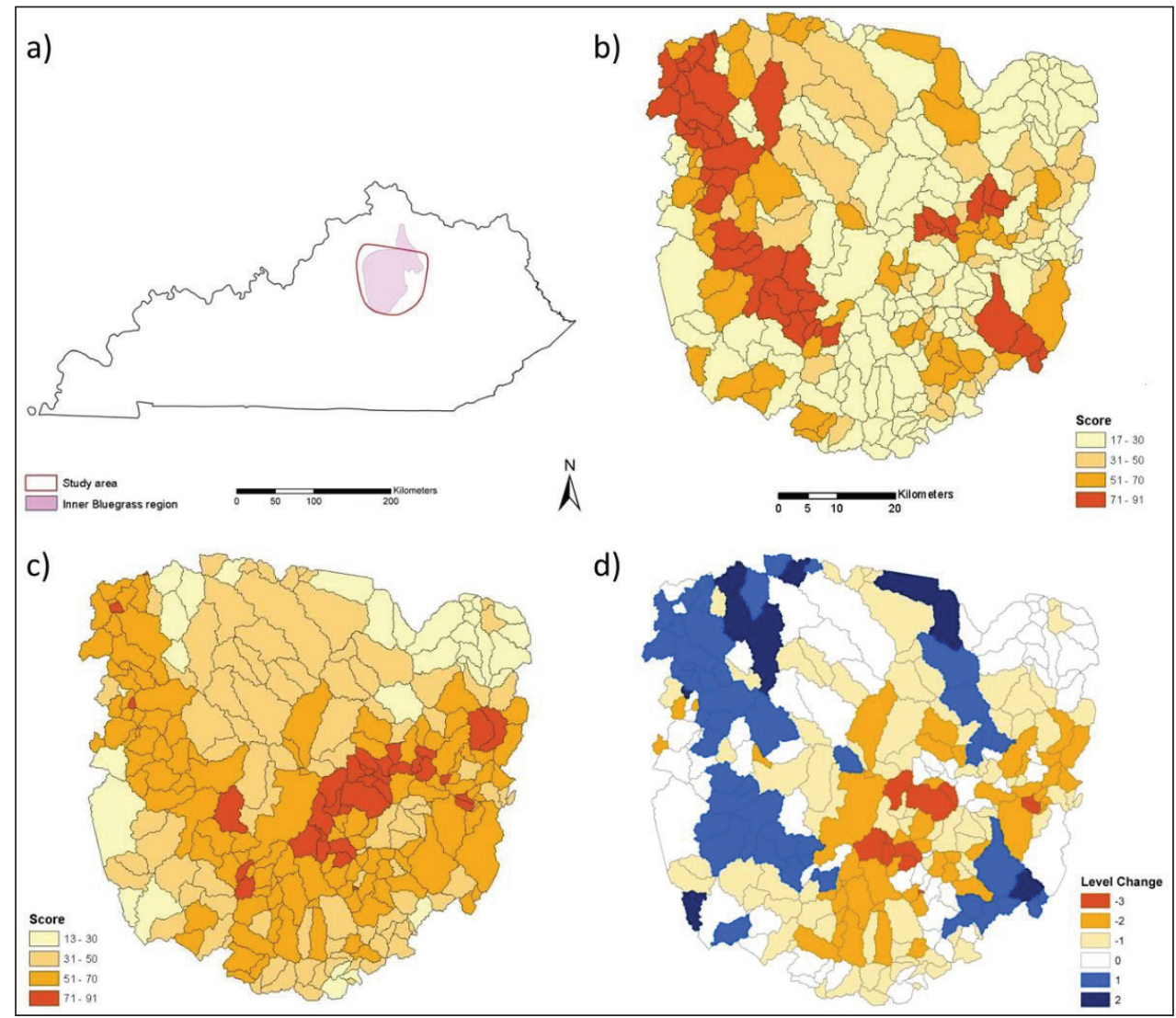

Figure I. a Location of study area created to fit the general outline of the Inner Bluegrass region of Kentucky. The priority scores calculated for $\mathbf{b}$ established invasion output and $\mathbf{c}$ new invasion output $\mathbf{d}$ The change in priority level between the established and new invasion scenarios.

output examined prioritization under the current stage of Amur honeysuckle invasion within the Inner Bluegrass region of Kentucky. This output was labeled the "established invasion scenario" (EIS) because Amur honeysuckle is widely established and distributed throughout this region, having high ecological and economic impacts. The second output examined prioritization under a hypothetical scenario, in which Amur honeysuckle was new to the region and only beginning invasion and early establishment. This output was labeled "new invasion scenario" (NIS) because it represented a hypothetical stage of invasion in which the density levels of Amur honeysuckle are much lower than what the region is currently experiencing. By using one tool to generate two outputs, we were also able to compare how a perceptual change in the stage of Amur honeysuckle invasion could alter parameter importance and management priority between outputs.

Parameters were organized into AHP using the software program Expert Choice decision software (Version 11.5, Arlington, VA). AHP analyzes the data by gather- 
Table I. Detailed description of data used in the AHP management tool. Parameters are organized into one of three categories, Invasive Exotic Plant (IEP) Attributes, Ecological Impacts, or Land Use Characteristics. The Description column gives details of data sources and how parameters were generated. The Attributes column details how parameters were divided and assigned to management units.

\begin{tabular}{|c|c|c|}
\hline $\begin{array}{l}\text { Category and } \\
\text { Parameter }\end{array}$ & Description & Attributes \\
\hline \multicolumn{3}{|l|}{ IEP Parameters } \\
\hline $\begin{array}{l}\text { Amur honeysuckle } \\
\text { density }\end{array}$ & $\begin{array}{c}\text { Estimated Amur honeysuckle density from } \\
\text { a supervised classification of a } 2009 \text { Landsat } \\
\text { satellite image }\end{array}$ & $\begin{array}{c}5 \text { density levels: lowest, low, medium, } \\
\text { high, highest }\end{array}$ \\
\hline $\begin{array}{c}\text { Young Amur } \\
\text { honeysuckle density }\end{array}$ & $\begin{array}{c}\text { Estimated young Amur honeysuckle density by } \\
\text { subtracting the } 2005 \text { distribution from the } 2009 \\
\text { distribution }\end{array}$ & $\begin{array}{c}5 \text { density levels: lowest, low, medium, } \\
\text { high, highest }\end{array}$ \\
\hline $\begin{array}{l}\text { High invasion } \\
\text { pressure }\end{array}$ & $\begin{array}{c}\text { Calculated average density of Amur honeysuckle } \\
\text { per watershed. Higher densities relate to higher } \\
\text { invasion pressure on neighboring watersheds }\end{array}$ & $\begin{array}{c}\text { Is the watershed neighboring a unit } \\
\text { with a higher than average density of } \\
\text { Amur honeysuckle? Yes or no }\end{array}$ \\
\hline \multicolumn{3}{|l|}{ Ecological Impacts } \\
\hline $\begin{array}{c}\text { Rarity-weighted } \\
\text { species richness index }\end{array}$ & $\begin{array}{l}\text { Presence/absence of rare species. Index created } \\
\text { by the Kentucky State Nature Preserves } \\
\text { Commission. Index incorporates the rare species } \\
\text { distribution and number of populations within } \\
\text { the state to create a rarity index score }\end{array}$ & $\begin{array}{c}5 \text { index levels: } \\
\text { High = high concentration of rare } \\
\text { species present } \\
\text { Medium = rare species present } \\
\text { Low = may support rare species, } \\
\text { though no occurrences are known } \\
\text { Historic = occurrences that have not } \\
\text { been observed for over } 20 \text { years } \\
\text { Absent = no rare species present or } \\
\text { historically documented }\end{array}$ \\
\hline $\begin{array}{c}\text { Ecologically } \\
\text { important sites }\end{array}$ & $\begin{array}{l}\text { Ecologically significant areas as identified by the } \\
\text { Kentucky State Nature Preserves Commission }\end{array}$ & $\begin{array}{l}\text { Does the watershed contain an } \\
\text { ecologically important area? Yes or no }\end{array}$ \\
\hline GAP diversity & $\begin{array}{c}\text { Generalized habitat diversity levels as modeled by } \\
\text { the GAP analysis program }\end{array}$ & 3 diversity levels: low, medium, high \\
\hline \multicolumn{3}{|l|}{$\begin{array}{c}\text { Land Use } \\
\text { Characteristics }\end{array}$} \\
\hline Land usage & $\begin{array}{l}\text { General land usage of each watershed derived } \\
\text { from Population Interaction Zones for } \\
\text { Agriculture (PIZA) created by the USDA }\end{array}$ & $\begin{array}{l}3 \text { zones: agricultural land, less } \\
\text { impacted land, highly urbanized land }\end{array}$ \\
\hline Road density & $\begin{array}{l}\text { Road dataset produced by the Kentucky } \\
\text { Transportation Cabinet }\end{array}$ & $\begin{array}{l}5 \text { density levels: lowest, low, medium, } \\
\text { high, highest }\end{array}$ \\
\hline
\end{tabular}

ing the parameters in a pair-wise manner, asking the user to rate which parameter is more important (and by how much) in meeting the assigned goal. For instance, the user would answer the question, "when prioritizing watersheds for Amur honeysuckle management, are the ecological impacts or the invader's attributes more important?" In this pairwise manner, all categories, parameters, and attributes were weighted. We used a natural resource manager and an ecologist to provide responses to the pairwise comparisons for both invasion scenarios. 


\section{Calculating management priority}

Attributes of each parameter were overlaid onto individual management units by using ArcGIS 10 Geospatial Modeling Environment (ESRI Inc., Redlands, CA). The 14-digit hydrological unit code (HUC), which refers to the finest scale for watershed delineation, was used to divide the study area into 286 management units. A priority score for each management unit was calculated by converting attribute weights into a point value and then totaling the points of all attributes within each unit $(\mathrm{Ou}$ et al, 2008). A total of 100 possible points was assigned among the three categories of the hierarchy based on the user generated weights. Points were then allocated to parameters and attributes based on user generated weights of importance. Management units with high total scores were deemed higher priority than those receiving lower scores. Management units were organized into one of four priority levels based on their total points (Table 2). Differences in distribution of priority between the two outputs allowed us to

Table 2. Scoring intervals organized into management priority levels. The higher the score, the higher the priority level assigned to the management unit.

\begin{tabular}{c|c|c}
\hline Scoring interval & Priority rank & Priority level \\
\hline $0-30$ & Lowest & 1 \\
\hline $31-50$ & Low & 2 \\
\hline $51-70$ & Medium & 3 \\
\hline $71-91$ & High & 4 \\
\hline
\end{tabular}

Table 3. The AHP results of the established invasion output. Weighted percentages of importance were assigned at the category level (IEP Parameters 24\%). Percentage points were further divided among parameters within each category (IEP density - 14). Points were then assigned to individual attributes that represented the characteristic of each management unit (Lowest -14).

\begin{tabular}{|c|c|c|}
\hline 1. IEP parameters $(24 \%)$ & 2. Ecological impacts $(66 \%)$ & 3. Land use characteristics $(10 \%)$ \\
\hline 1.1 IEP density (14) & 2.1 Rarity-weighted richness (32) & 3.1 Land usage (6) \\
\hline Lowest 14 & High 32 & Agriculture 1 \\
\hline Low 10 & Medium 28 & Less impacted 6 \\
\hline Medium 5 & Low 14 & Highly urban 2 \\
\hline High 2 & Historic 7 & \\
\hline \multirow[t]{2}{*}{ Highest 0} & Absent 0 & 3.2 Road density (4) \\
\hline & & Lowest 4 \\
\hline 1.2 Young IEP density (6) & 2.2 Ecologically important site (27) & Low 3 \\
\hline Lowest 1 & Yes 27 & Medium 2 \\
\hline Low 2 & No 0 & High 1 \\
\hline Medium 3 & & Highest 0 \\
\hline High 4 & 2.3 GAP diversity (7) & \\
\hline \multirow[t]{2}{*}{ Highest 6} & Low 1 & \\
\hline & Medium 4 & \\
\hline 1.3 High invasion pressure (4) & High 7 & \\
\hline Yes 4 & & \\
\hline No 1 & & \\
\hline
\end{tabular}


analyze how altering user input based on invasion stage impacted priority. The results of the two prioritizations were analyzed in ArcGIS by comparing changes in each management unit's score and priority level between the outputs.

\section{Results}

The AHP successfully produced two distinct prioritizations from one tool, demonstrating a useful flexibility. Between the two invasion scenarios, users were able to weight the importance of the parameters differently dependent upon the stages of Amur honeysuckle invasion. For the EIS output, the Ecological Impacts category was weighted the highest (66\%), followed by IEP Parameters (24\%), and Land Use Characteristics (10\%) (Table 3). Parameters listed in the order of deemed importance were the rarity weighted species richness index, followed by ecologically important sites, and Amur honeysuckle density. The remaining five parameters had limited influence, with high invasion pressure and road density deemed the least important when considering management priority.

For the hypothetical NIS output, the IEP Parameters category was weighted highest (62\%), followed by Land Use Characteristics (29\%), and Ecological Impacts (9\%) (Table 4). Within the categories, the five highest parameters were Amur honeysuckle density, followed by young Amur honeysuckle density, land cover, road density, and

Table 4. The AHP results of the new invasion output. Weighted percentages of importance were assigned at the category level (IEP Parameters 62\%). Percentage points were further divided among parameters within each category (IEP density - 30). Points were then assigned to individual attributes that represented the characteristic of each management unit (Lowest - 6).

\begin{tabular}{c|c|c}
\hline 1. IEP parameters (62\%) & 2. Ecological impacts (9\%) & 3. Land use characteristics (29\%) \\
\hline 1.1 IEP density (30) & 2.1 Rarity-weighted richness (4) & 3.1 Land usage (17) \\
\hline Lowest 6 & High 4 & Agriculture 1 \\
\hline Low 14 & Medium 3 & Less impacted 12 \\
\hline Medium 19 & Low 2 & Highly urban 17 \\
\hline High 25 & Historic 1 & 3.2 Road density (12) \\
\hline Highest 30 & Absent 0 & Lowest 1 \\
\hline 1.2 Young IEP density (21) & 2.2 Ecologically important site (4) \\
\hline Lowest 4 & Yes 4 & Medium 7 \\
\hline Low 10 & No 0 & High 10 \\
\hline Medium 15 & & \\
\hline High 19 & 2.3 GAP diversity (1) & \\
\hline Highest 21 & Low 1 & \\
\hline & Medium 1 & \\
\hline 1.3 High invasion pressure (11) & High 1 & \\
\hline Yes 11 & & \\
\hline No 1 & &
\end{tabular}


high invasion pressure. The remaining three parameters had little influence on the prioritization, with GAP (Gap Analysis Program) diversity being weighted the lowest.

Clear differences in the spatial distribution of priority areas were observed between the two outputs (Figure 1b-d). For the EIS output, the top priority units were generally found within a western strip of the study area (Figure 1b). For the NIS output, the top priority units were in a tight cluster within the center of the study area (Figure 1c). Because of these distinct differences in priority, we quantified the changes in priority distribution (Figure 1d). The greatest change in priority score between outputs was 58 points. The majority of changes in priority level were from instances where units that received low scores in the EIS output received high scores in the NIS output.

\section{Discussion}

\section{Comparison of invasion scenarios}

The ability of a user to compare parameter importance within each respective category is vital to producing a flexible tool for management. Users altered which parameters they believed were most important for prioritizing management sites dependent upon the stage of invasion. In the EIS output where Amur honeysuckle has long been established and widespread, priority was weighted towards removing the invader from the most ecologically significant areas. After deeming the Ecological Impacts category as most important, users decided that the presence/absence of rare species and ecologically important areas should receive more weight than the GAP diversity parameter.

Outside of the Ecological Impacts category, users also deemed that the distribution and density of Amur honeysuckle as important information. User input suggested that management units with lower Amur honeysuckle density were most important because these sites would be easier to manage, resulting in a better possibility for control. The other parameters, which related to spread and establishment, were not as important in this output because of the widespread establishment of the invader.

In the NIS output, priority was shifted from primarily protecting ecologically important areas to relying on parameters that would lead to monitoring of high risk sites and quick removal of new invasions. The IEP Parameters category was most important in this output because it would allow managers to locate such areas of new establishment and remove the invader before it spreads. In addition, users weighted the Land Use Characteristics category higher because its parameters may lead to monitoring and prevention of introduction. For instance, the land usage and road density parameters identify areas of increased disturbance, which may relate to a higher probability of introduction or establishment. Rather than focusing on potential impacts in a scenario of newly invading Amur honeysuckle, users suggested that in an effort to eradicate the invader, it was more important to focus activities on removing current stands while also directing operations to monitor and/or prevent new introductions. 


\section{AHP management tool}

For this assessment, we chose to demonstrate the AHP management tool at the landscape scale and used watersheds as management boundaries. It is important to address the landscape level because the risk of invasion is often related to its environmental factors (With 2002). We are acknowledging that certain landscapes may be more vulnerable to invasion and experience various levels of impacts. Likewise, prioritization at the this level can facilitate eradication of the most ecologically damaging populations, while creating a system that uses limited labor in areas of most need. Furthermore, watersheds are highly recognizable by managers and make realistic boundaries at this scale. By operating at a landscape scale, we were able to use readily available GIS data to create many of our parameters. Many state agencies have websites dedicated to sharing ecologically relevant data at this scale. Finally, changes in parameter importance between the two outputs demonstrate the importance of using data that broadly cover the entire invasion process.

We acknowledge that the AHP outputs were only generated from two users. While the management tool was not demonstrated by multiple user groups we believe that our results show that AHP is capable of producing flexible outputs for prioritizing management. Our assessment of AHP flexibility, along with other region and species-specific AHP frameworks (e.g., Skurka Darin et al. 2011, Hohmann et al. 2013, Robison et al. 2013) will greatly enrich managers options in invasive species management decision making.

\section{Management implications and conclusion}

Our results demonstrate the flexibility of the AHP management tool, which is important for managers. Managers can create a unique AHP framework around their management scenario and needs by incorporating appropriate data that best fit the target invader. The tool could also be adjusted to meet various management scales by changing data sources between county, state, or regional levels. The AHP management tool may be especially useful for managers in situations where work proposals are required before implementation. In such cases, a manager could use one basic tool to propose multiple prioritizations based upon the various goals within the organization. Managers could also demonstrate how management might change dependent on potential budgets, priority between ecological protection or economic feasibility, or preference between eradication or control of spread. Equipped with more information, comparisons and decisions can be made that best meet each unique management situation.

Overall, there is a need for information-driven tools to assist management decision-making. Invasive plant management at the landscape scale is often complex and should include data relevant from all stages of the invasion process. AHP as a tool is guided by the user's expert knowledge and allows the user to assess large amounts of data in a structured environment. In addition, AHP provides valuable transparency to the decision making process. Various frameworks have been constructed that successfully demonstrate the usefulness of the AHP tool for addressing specific management 
questions. By successfully demonstrating the flexibility of AHP across two different invasion scenarios, our results indicate that AHP has the potential to meet management needs for prioritizing invasive plant management.

\section{Acknowledgments}

The research was partially supported by NSF (DEB-12108803). The authors thank Dr. Liang Liang and Dr. Mary Arthur of the University of Kentucky for support and comments on this research. We also thank Dr. Ryan McEwan of the University of Dayton and Joyce Bender of the Kentucky State Nature Preserves Commission for providing the user input for the AHP. Finally, we thank the Kentucky State Nature Preserves Commission for data provided for this study.

\section{References}

Byers JE, Reichard S, Randall JM, Parker IM, Smith CS, Lonsdale WM, Atkinson IAE, Seastedt TR, Williamson M, Chornesky E, Hayes D (2002) Directing research to reduce the impacts of nonindigenous species. Conservation Biology 16: 630-640. doi: 10.1046/j.15231739.2002.01057.x

Cook D, Thomas M, Cunningham S, Anderson D, De Barro P (2007) Predicting the economic impact of an invasive species on an ecosystem service. Ecological Applications 17: 1832-1840. doi: 10.1890/06-1632.1

Cunningham DC, Barry SC, Woldendorp G, Burgess MB (2004) A framework for prioritizing sleeper weeds for eradication. Weed Technology 18: 1189-1193. doi: 10.1614/0890-037x( 2004)018[1189:affpsw]2.0.co;2

Dutra H, Barnett K, Reinhardt J, Marquis R, Orrock J (2011) Invasive plant species alters consumer behavior by providing refuge from predation. Oecologia 166: 649-657. doi: 10.1007/s00442-010-1895-7

Ehrenfeld JG (2010) Ecosystem Consequences of Biological Invasions. Annual review of ecology, evolution, and systematics 41: 59-80. doi: 10.1146/annurev-ecolsys-102209-144650

Fei S, Phillips J, Shouse M (2014) Biogeomorphic impacts of invasive species. Annual review of ecology, evolution, and systematics 45: 69-87. doi: 10.1146/annurev-ecolsys-120213-091928

Forsyth GG, Le Maitre DC, O'Farrell PJ, van Wilgen BW (2012) The prioritisation of invasive alien plant control projects using a multi-criteria decision model informed by stakeholder input and spatial data. Journal of Environmental Management 103: 51-57. doi: 10.1016/j.jenvman.2012.01.034

Gorchov D, Trisel D (2003) Competitive effects of the invasive shrub, Lonicera maackii (Rupr.) Herder (Caprifoliaceae), on the growth and survival of native tree seedlings. Plant Ecology 166: 13-24. doi: 10.1023/A:1023208215796 
Hiebert RD (1997) Prioritizing invasive plants and planning for management. In: Luken J, Thieret J (Eds) Assessment and management of plant invasions. Springer, New York, 195212. doi: 10.1007/978-1-4612-1926-2_15

Hohmann MG, Just MG, Frank PJ, Wall WA, Gray JB (2013) Prioritizing invasive plant management with multi-criteria decision analysis. Invasive Plant Science and Management 6: 339-351. doi: 10.1614/IPSM-D-11-00080.1

McKinney A, Goodell K (2010) Shading by invasive shrub reduces seed production and pollinator services in a native herb. Biological Invasions 12: 2751-2763. doi: 10.1007/s10530009-9680-4

Mehta SV, Haight RG, Homans FR, Polasky S, Venette RC (2007) Optimal detection and control strategies for invasive species management. Ecological Economics 61: 237-245. doi: 10.1016/j.ecolecon.2006.10.024

Moilanen A, Franco AM, Early RI, Fox R, Wintle B, Thomas CD (2005) Prioritizing multiple-use landscapes for conservation: methods for large multi-species planning problems. Proceedings of the Royal Society of London B: Biological Sciences 272: 1885-1891. doi: 10.1098/rspb.2005.3164

Ou J, Lu C, O'toole DK (2008) A risk assessment system for alien plant bio-invasion in Xiamen, China. Journal of Environmental Sciences 20: 989-997. doi: 10.1016/S10010742(08)62198-1

Pert PL, Lieske SN, Hill R (2013) Participatory development of a new interactive tool for capturing social and ecological dynamism in conservation prioritization. Landscape and Urban Planning 114: 80-91. doi: 10.1016/j.landurbplan.2013.02.010

Peterson DP, Wenger SJ, Rieman BE, Isaak DJ (2013) Linking climate change and fish conservation efforts using spatially explicit decision support tools. Fisheries 38: 112-127. doi: 10.1080/03632415.2013.769157

Ricciardi A, Hoopes MF, Marchetti MP, Lockwood JL (2013) Progress toward understanding the ecological impacts of nonnative species. Ecological Monographs 83: 263-282. doi: 10.1890/13-0183.1

Robison R, Barve N, Owens C, Skurka Darin G, DiTomaso J (2013) Mapping and eradication prioritization modeling of red sesbania (Sesbania punicea) populations. Environmental Management 52: 19-28. doi: 10.1007/s00267-013-0063-3

Roura-Pascual N, Richardson DM, Krug RM, Brown A, Chapman RA, Forsyth GG, Le Maitre DC, Robertson MP, Stafford L, Van Wilgen BW, Wannenburgh A, Wessels N (2009) Ecology and management of alien plant invasions in South African fynbos: Accommodating key complexities in objective decision making. Biological Conservation 142: 15951604. doi: 10.1016/j.biocon.2009.02.029

Saaty T, Vargas LLG (2001) Models, methods, concepts, and applications of the analytic hierarchy process. Springer. doi: 10.1007/978-1-4615-1665-1

Sarakinos H, Nicholls AO, Tubert A, Aggarwal A, Margules CR, Sarkar S (2001) Area prioritization for biodiversity conservation in Québec on the basis of species distributions: a preliminary analysis. Biodiversity \& Conservation 10: 1419-1472. doi: 10.1023/A:1011871723686 
Simberloff D, Martin J-L, Genovesi P, Maris V, Wardle DA, Aronson J, Courchamp F, Galil B, García-Berthou E, Pascal M (2012) Impacts of biological invasions: What's what and the way forward. Trends in Ecology \& Evolution 28: 58-66. doi: 10.1016/j.tree.2012.07.013

Skinner K, Smith L, Rice P (2000) Using noxious weed lists to prioritize targets for developing weed management strategies. Weed Science 48: 640-644. doi: 10.1614/0043-1745(2000)048[0640:UNWLTP]2.0.CO;2

Skurka Darin GM, Schoenig S, Barney JN, Panetta FD, DiTomaso JM (2011) WHIPPET: A novel tool for prioritizing invasive plant populations for regional eradication. Journal of Environmental Management 92: 131-139. doi: 10.1016/j.jenvman.2010.08.013

Taylor CM, Hastings A (2004) Finding optimal control strategies for invasive species: A density-structured model for Spartina alterniflora. Journal of Applied Ecology 41: 1049-1057. doi: 10.1111/j.0021-8901.2004.00979.x

Valente ROA, Vettorazzi CA (2008) Definition of priority areas for forest conservation through the ordered weighted averaging method. Forest Ecology and Management 256: 1408-1417. doi: 10.1016/j.foreco.2008.07.006

Watling JI, Hickman CR, Orrock JL (2011) Invasive shrub alters native forest amphibian communities. Biological Conservation 144: 2597-2601. doi: 10.1016/j.biocon.2011.07.005

Wharton ME, Barbour RW (1991) Bluegrass land \& life: Land character, plants, and animals of the Inner Bluegrass Region of Kentucky, past, present, and future. University Press of Kentucky Lexington.

With KA (2002) The landscape ecology of invasive spread. Conservation Biology 16: 1192-1203. doi: 10.1046/j.1523-1739.2002.01064.x

Zelenović Vasiljević T, Srdjević Z, Bajčetić R, Vojinović Miloradov M (2012) GIS and the analytic hierarchy process for regional landfill site selection in transitional countries: A case study from Serbia. Environmental Management 49: 445-458. doi: 10.1007/s00267-0119792-3 